\title{
Characterization of ovarian cancer cells and tissues by Fourier transform infrared spectroscopy
}

\author{
Lei Li ${ }^{1}$, Xiaoning Bi ${ }^{1}$, Hengzi Sun', Simiao Liu', Mei Yu', Ying Zhang ${ }^{1}$, Shifu Weng ${ }^{2}$, Limin Yang ${ }^{3}$, Yanan Bao ${ }^{2}$, \\ Jinguang $\mathrm{Wu}^{2}$, Yizhuang $\mathrm{Xu}^{2^{*}}$ and Keng Shen ${ }^{1^{*}}$
}

\begin{abstract}
Background: Ovarian cancer is the most lethal of gynecological malignancies. Fourier Transform Infrared (FTIR) spectroscopy has gradually developed as a convenient, inexpensive and non-destructive technique for the study of many diseases. In this study, FTIR spectra of normal and several heterogeneous ovarian cancer cell lines as well as ovarian cancer tissue samples were compared in the spectral region of $4000 \mathrm{~cm}^{-1}-600 \mathrm{~cm}^{-1}$.

Methods: Cell samples were collected from human ovarian surface epithelial cell line (HOSEpiC) and five ovarian cancer cell lines (ES2, A2780, OVCAR3, SKOV3 and IGROV1). Validation spectra were performed on normal and cancerous tissue samples from 12 ovarian cancer patients. FTIR spectra were collected from a NICOLET iN10 MX spectrometer and the spectral data were analyzed by OMNIC 8.0 software.

Results: Spectral features discriminating malignant tissues from normal tissues were integrated by cell line data and tissue data. In particular changes in cancerous tissues, the decrease in the amount of lipids and nucleic acids were observed. Protein conformation and composition were also altered in some cancer cells. The band intensity ratio of 1454/1400 was higher in normal cells/tissues and lower in cancer cells/tissues.

Conclusion: The spectral features revealed the important molecular characteristics about ovarian cancer cells/ tissues. These findings demonstrate the possible diagnostic use of FTIR spectroscopy, providing the research model and evidences, and supporting the future study on more tissue samples to establish a data bank of spectra features for the possible discrimination of ovarian cancers.
\end{abstract}

Keywords: Ovarian cancer, Fourier transform infrared (FTIR) spectroscopy, Tumor heterogeneity, Clinical diagnosis

\section{Background}

Ovarian cancer is associated with the worst prognosis among gynecological malignancies, accounting for more than 150,000 deaths annually worldwide [1]. Most patients with advanced stages of ovarian cancer result in five-year survival rates less than 30\% [2]. Ovarian cancer includes several heterogeneous subtypes with different

\footnotetext{
* Correspondence: xuyzh_peking@sina.com; kengshen_pumch@sina.com ${ }^{2}$ Beijing National Laboratory for Molecular Sciences, State Key Laboratory for Rare Earth Materials Chemistry and Applications, College of Chemistry and Molecular Engineering, Peking University, No. 202 Chengfu Road, Haidian District, Beijing 100871, China

${ }^{1}$ Department of Obstetrics and Gynecology, Peking Union Medical College Hospital, Chinese Academy of Medical Sciences \& Peking Union Medical College, No. 1 Shuai Fu Yuan, Eastern District, Beijing 100730, China
} Full list of author information is available at the end of the article clinical phenotypes, molecular features and prognosis. About $90 \%$ are epithelial ovarian cancers (EOC) [3], which is traditionally subtyped as serous, endometrioid, clear cell and mucinous. Among them, serous ovarian cancer accounts for about 70\% of EOC [4]. High-grade serous ovarian cancer (HGSOC), the most malignant subtype, is responsible for $90 \%$ of serous tumors [5]. Developing methods for detecting ovarian cancer at the early stage and illuminating the molecular mechanism underlying this tumor heterogeneity would provide us new insights into ovarian cancer and lead to more effective diagnostic approaches.

Currently, there are two approaches available for diagnosing ovarian cancer patients. One is the detection of the blood-derived biomarkers. The frequently used 
biomarker is serum Cancer Antigen 125 (CA-125) [6]. However, limited specificity exists in this method as CA-125 level also rises in some other types of cancers and also fluctuates in premenopausal women during menstrual cycle [7]. The other method is to provide detailed images of ovaries through imaging techniques such as Magnetic Resonance Imaging (MRI), Doppler Ultrasound and Computed Tomography (CT). However, ultrasound shows a poor accuracy in diagnosing diseases at early stages [8]. It is obvious that these current methods have some limitations. Therefore new insights are needed to identify novel methods for detecting and categorizing ovarian cancer patients.

Vibrational spectroscopy is one kind of the bio-analytical methods that increasingly shows significant potential to provide a novel diagnostic tool to distinguish normal and pathological tissues [9]. Fourier-transform infrared (FTIR) spectroscopy, in particular, has been utilized in the past several decades [10-12]. It has the advantage of convenience and non-destruction to detect tumors with minimal sample preparations, and also allows the investigation of both qualitative and quantitative assesses of certain components [13, 14].

Many studies by this technique have been focused on several cancer cells or tissues, such as endometrial [15], cervical [16], breast [17], lung [18] and brain cancers [19]. Few studies have screened ovarian cancer by FTIR. Gajjar et al. [20], Owens et al [21] and Lima et al [22] have respectively examined blood plasma or serum of ovarian cancer by attenuated total reflection Fourier-transform infrared (ATR-FTIR) spectroscopy coupled with other selection methods. Mehrotra et al [23] analyzed FTIR data of the post surgical tissue sections of ovarian cancer and discovered some particular changes in the spectral regions of protein, nucleic acid and lipid, using 12 samples without classifying the cancer subtype. Theophilou et al [24] provided a novel approach in discriminating normal, borderline and malignant ovarian tissues. The authors used ATR-FTIR spectroscopy combined with three chemometric methods followed by linear discriminant analysis. However, there were little common insights in these few studies, as they explored on different aspects. In the present study, we fundamentally focused on EOC with respect to its normal and several heterogeneous cancer cell line models using FTIR technique and confirmed the results by several tissue samples, providing proof of principal that there were differences between EOC and healthy donor epithelium and supporting the future study to move to more clinical tissue samples to establish a data bank of spectra features.

\section{Methods}

\section{Cell culture}

The normal cell line used in this study was human ovarian surface epithelial cell line (HOSEpiC) obtained from
ScienCell Research Laboratories (San Diego, CA). The ovarian cancer cell lines used in this study were ES2, A2780, OVCAR3, SKOV3 and IGROV1. Among them, ES2, A2780 and SKOV3 were purchased from the Cell Support Center, Institute of Basic Medical Science, Chinese Academy of Medical Sciences; OVCAR3 and IGROV1 were purchased from the NIH cell bank. OVCAR3 originates from the malignant ascites of a patient with ovarian adenocarcinoma [25], possesses characteristics of HGSOC [26]. ES2 is a recognized ovarian clear cell carcinoma cell line [27]. IGROV1, originating from an ovarian carcinoma of a 47-year-old woman, is an ovarian adenocarcinoma cell line with multiple differentiations, and endometrioid is its major part [28]. A2780 and SKOV3 both have been widely used as models for HGSOC. However, recent studies demonstrated that they carried some characteristics of endometrioid/clear cell ovarian carcinomas [26].

HOSEpiC, A2780, IGROV1 and OVCAR3 cells were incubated in Roswell Park Memorial Institute (RPMI)-1640 medium (HyClone, Logan, Utah, USA) supplemented with $15,10,10$ and $20 \%$ heat-inactivated fetal bovine serum (FBS; Gibco, Carlsbad, CA, USA), respectively, at $37^{\circ} \mathrm{C}$ in $5 \%$ carbon dioxide. ES2 and SKOV3 cells were cultured in McCoy's 5A medium (HyClone) containing 10\% FBS at $37{ }^{\circ} \mathrm{C}$ in $5 \%$ carbon dioxide. The cells were subcultured when they reached approximately $80 \%$ confluence, and harvested at almost the same life time after two passages.

\section{Cell preparation for spectroscopy}

Cells were trypsinized and washed twice in saline, suspended and centrifuged at $1000 \mathrm{rpm}$ for $5 \mathrm{~min}$. Supernatant was then removed gently and cells were stored at $-80^{\circ} \mathrm{C}$ until removal for experiments.

\section{Tissue collection and preparation for spectroscopy}

Tissue specimens from 12 cases of EOC were obtained from Peking Union Medical College Hospital, Chinese Academy of Medical Sciences \& Peking Union Medical College. Informed consents have been taken before surgery. Cancer tissue and their corresponding normal tissue samples were collected respectively from 10 histologically serous cancer and 2 clear cell cancer patients. Tissue samples were frozen at $-80{ }^{\circ} \mathrm{C}$ until removal for spectral scanning.

\section{FTIR spectroscopy}

FTIR spectra of cell and tissue samples were collected using a NICOLET iN10 MX (Thermo Scientific, Waltham, MA, USA) spectrometer, equipped with a $\mathrm{KBr} / \mathrm{Ge}$ beam splitter and a mercury cadmium telluride (MCT) detector. For each spectrum, 16 scans were performed at the resolution of $4 \mathrm{~cm}^{-1}$ between $4000 \mathrm{~cm}^{-1}$ and $600 \mathrm{~cm}^{-1}$. The spectrum was then baseline corrected 
and normalized from 0 to 1 so as to have better comparison for the intensity.

\section{Analysis of FTIR data}

Second Derivative (DII) and Curve Fitting (Gaussian algorithm) procedures were performed to identify the precise position and absorbance of specific bands. By using OMNIC 8.0 software (Thermo Fisher Scientific), Curve Fitting was conducted on spectra in the range of $1700-1600 \mathrm{~cm}^{-1}$ after two points baseline linear fitted. In order to determine the underlying component bands, the number of peaks as well as their positions was identified based on DII results, resulting in the optimal reconstructed curve (residual close to zero). Positions and percentages of band areas were obtained for every component peak.

\section{Subtraction spectra}

In order to further identify spectral variations between normal cells and ovarian cancer cells, the spectrum of ovarian surface epithelial cell line (HOSEpiC) was subtracted by the spectrum of each of the ovarian cancer cell lines, respectively. Thus we obtained the "subtraction spectra". All of the subtraction spectra were calculated using fully preprocessed spectra, that were baseline corrected and normalized from 0 to 1 .

\section{Statistical analysis}

The percentages of band areas are presented as mean \pm SEM. For statistical comparisons among multiple cell lines, one-way ANOVA test was used by SPSS 17.0 software (Chicago, Illinois, USA) with a significance set at $P<0.05$ for at least three times. For statistical comparisons of spectra intensities between normal and malignant tissues at specific bands, a Wilcoxon paired signed-rank test with a significant level of 0.05 was used by SPSS 17.0 software.

\section{Results}

FTIR spectral analysis for normal and ovarian cancer cell lines

This study first focused on the biochemical differences between several heterogeneous ovarian cancer cell lines (ES2, A2780, OVCAR3, SKOV3 and IGROV1) and the normal human ovarian surface epithelial cell line (HOSEpiC) by FTIR spectroscopy. For each cell line, a typical spectrum was presented (Fig. 1). The apparent spectral differences were observed, above all in the $\mathrm{C}-\mathrm{H}$ stretching region of fatty acids in cell membranes (3000-2800 $\mathrm{cm}^{-1}$ ), in the ester $\mathrm{C}=\mathrm{O}$ stretching of phospholipids $\left(1800-1700 \mathrm{~cm}^{-1}\right)$ and in the $\mathrm{C}-\mathrm{H}$ bending vibrations of amino acid side chains and some lipids $\left(1500-1300 \mathrm{~cm}^{-1}\right)$ [29]. Relative band intensities, which could be considered as spectral features for normal and cancer cells, were calculated. Second Derivative (DII) and Curve Fitting procedures of $1700-1600 \mathrm{~cm}^{-1}$ were used to investigate Amide I of protein, and subtraction spectra were performed in the region of $4000-600 \mathrm{~cm}^{-1}$ for additional comparison of each ovarian cancer cells versus normal cells.

\section{Comparison of the relative intensities of the specific bands for normal and ovarian cancer cell lines}

Several spectral markers for cancer cell lines differed considerably from normal cell line, as shown in Fig. 2. The band signals at $2958 \mathrm{~cm}^{-1}$ and $2925 \mathrm{~cm}^{-1}$ ( $v_{\text {asym }}$ $\mathrm{CH}_{3}$ and $\left.\mathrm{CH}_{2}\right), 2872 \mathrm{~cm}^{-1}$ and $2854 \mathrm{~cm}^{-1}\left(v_{\text {sym }} \mathrm{CH}_{3}\right.$ and $\mathrm{CH}_{2}$ ) are characteristics of alkyl chains mainly present in lipids [30]. After analyzing the relative band intensities, lower amounts of the relative intensities of $2925 \mathrm{~cm}^{-1}$ and $2854 \mathrm{~cm}^{-1}$ were found in the five cancer cells as compared to HOSEpiC cells, respectively (Fig. 2a, b), consisting with their corresponding FTIR spectra in the region of $3000-2800 \mathrm{~cm}^{-1}$ (Fig. 3a). The differences were significant for ES2, A2780, OVCAR3 and IGROV1 vs. HOSEpiC, respectively, indicating a lower amount of lipids present in the four cancer cells. Moreover, ovarian cancer cell lines also showed heterogeneous characteristics between themselves. ES2 showed lower relative intensity at $2925 \mathrm{~cm}^{-1}$ than that of OVCAR3, SKOV3 and IGROV1, respectively. The relative intensity at $2925 \mathrm{~cm}^{-1}$ in A2780 was significantly lower from that in SKOV3, while the relative intensity at $2854 \mathrm{~cm}^{-1}$ in ES2 was significantly lower from that in SKOV3 (Fig. 2a, b).

The absorption bands at $1242 \mathrm{~cm}^{-1}\left(v_{\mathrm{as}} \mathrm{PO}_{2}^{-}\right)$and $1086 \mathrm{~cm}^{-1}\left(v_{\mathrm{s}} \mathrm{PO}_{2}^{-}\right)$were attributed to asymmetric and symmetric phosphodiester vibrations of nucleic acids [31]. The relative intensity at $1242 \mathrm{~cm}^{-1}$ in OVCAR3 was lower than that in HOSEpiC, A2780, SKOV3 and IGROV1, respectively (Fig. 2d). A2780 showed lower relative intensity at $1086 \mathrm{~cm}^{-1}$ than that of OVCAR3, SKOV3 and IGROV1, while ES2 showed lower relative intensity at $1086 \mathrm{~cm}^{-1}$ than that of SKOV3 and IGROV1 (Fig. 2e). The differences were all significant. These findings also suggested heterogeneous characteristics between ovarian cancer cells.

In the absorption signals between 1800 and $1700 \mathrm{~cm}^{-}$ 1 , the prominent band intensity difference was found around $1741 \mathrm{~cm}^{-1}$, which was attributed to ester $\mathrm{C}=\mathrm{O}$ stretching of phospholipids [32, 33]. It is obvious that the signal at $1741 \mathrm{~cm}^{-1}$ was enhanced in HOSEpiC cells than in all of the ovarian cancer cells (Fig. 2c, Fig. 3b), indicating increased lipids and esterified components in cell membranes in normal ovarian cells than in cancerous cells. This result was in corroboration with the previous finding in breast cancer cells that the peak at $1741 \mathrm{~cm}^{-1}$ increased progressively with the increasing 


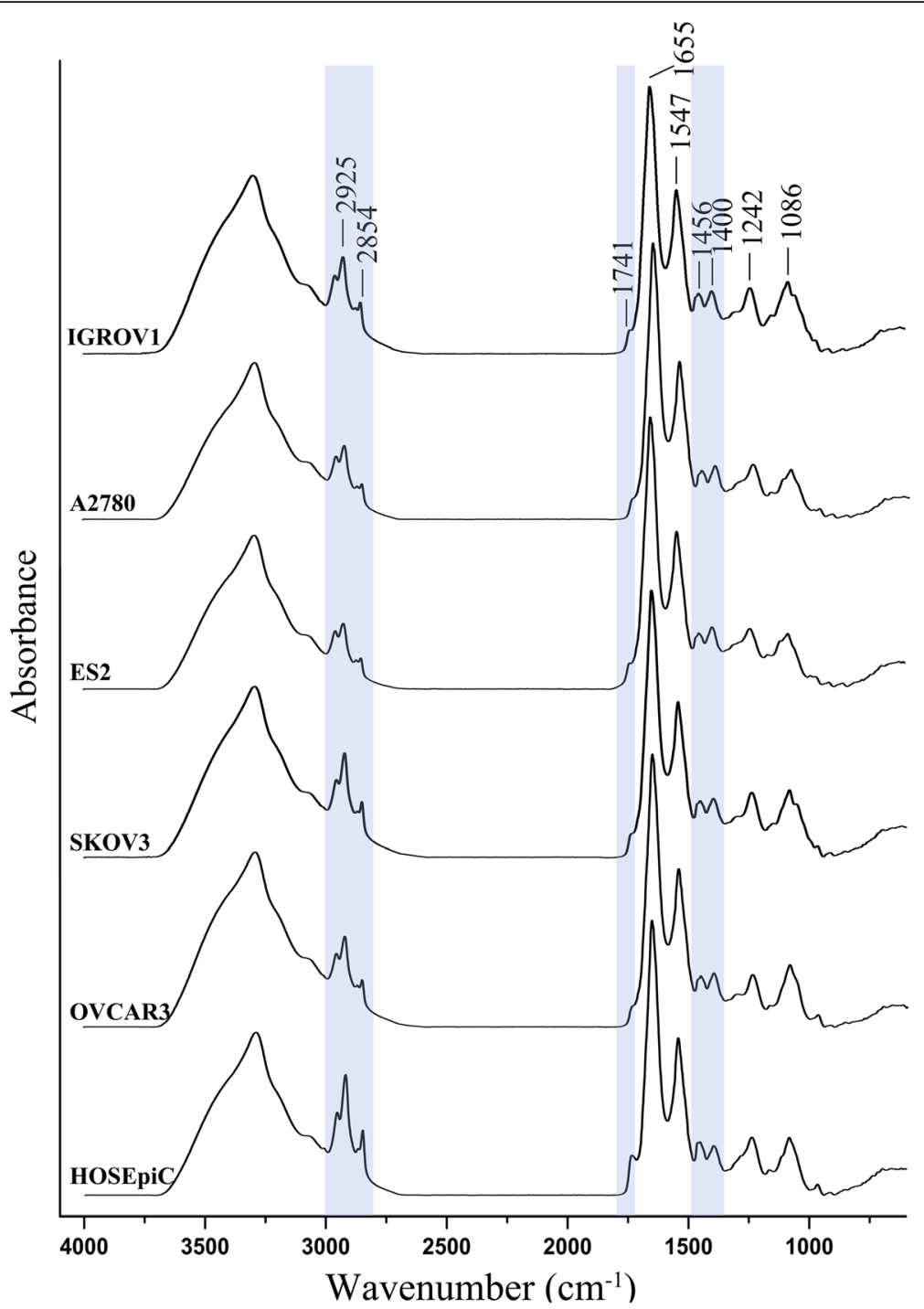

Fig. 1 Representative FTIR spectra of ovarian cancer cells and normal cells. FTIR spectra of the five ovarian cancer cell lines (IGROV1, A2780, ES2, SKOV3 and OVCAR3) and the normal human ovarian surface epithelial cell line (HOSEpiC) were presented in the region $4000-600 \mathrm{~cm}^{-1}$. The apparent differences were indicated in blue box

5-fluorouracil dose in MCF-7 cells (human breast adenocarcinoma cell line) [34]. As 5-fluorouracil overtly inhibited tumor cell proliferation in a concentration dependent manner, cells with the high level of proliferation showed the lower peak at $1741 \mathrm{~cm}^{-1}$, correspondence with our result that the malignant ovarian cancer cells exhibited lower intensities at $1741 \mathrm{~cm}^{-1}$ than normal ovarian cells.

The bands at 1454 and $1400 \mathrm{~cm}^{-1}$ usually attribute to the $\mathrm{C}-\mathrm{H}$ bending vibrations of various amino acid side chains and some lipids, etc. [29]. They are critical bands to distinguish normal and malignant tissues, and the precise assignments are not clear [35]. It is obvious to see that the band height at $1454 \mathrm{~cm}^{-1}$ was always lower than that at $1400 \mathrm{~cm}^{-1}$ in all of the ovarian cancer cell lines $\left(I_{1454} / I_{1400}<1\right)$. In HOSEpiC cells, comparison of the heights of the two bands were apparently opposite $\left(I_{1454} / I_{1400}>1\right)$. Besides, ES2 exhibited the lowest ratio of 1454/1400 among other cells (Fig. 2f, Fig. 3c).

\section{Curve fitting of protein amide I in normal and ovarian cancer cell lines}

The region between $1700 \mathrm{~cm}^{-1}$ and $1500 \mathrm{~cm}^{-1}$ was usually assigned to protein absorption with dominant bands at $\sim 1655 \mathrm{~cm}^{-1}$ (Amide I) and $\sim 1547 \mathrm{~cm}^{-1}$ (Amide II) [36]. After the Curve Fitting procedure, Amide I of the cells was analyzed respectively and split into a series of bands. In general for Amide I, $\alpha$-helical structures have a band at $1653 \pm 4 \mathrm{~cm}^{-1}$; $\beta$-sheet structures occurs between 1620 and $1640 \mathrm{~cm}^{-1}$; $\beta$-turn structures are usually found at $1660-1680 \mathrm{~cm}^{-1}$ [37]. The percentage of 

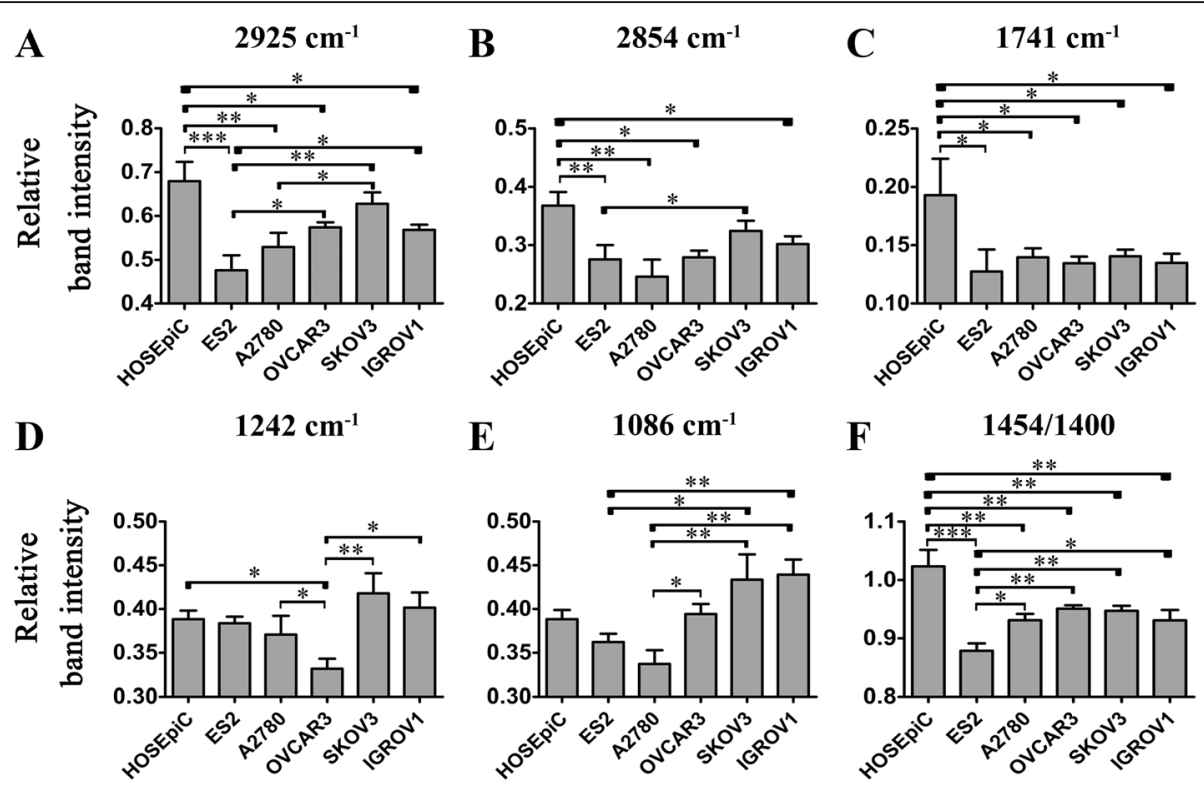

Fig. 2 Relative band intensitie of normal cells and ovarian cancer cells. Error bars represent the SEM, $n=3$ (*: $P<0.05$. **: $P<0.01$. ***: $P<0.001)$

the component band areas, representative of their relative amounts, was calculated (Table 1). The band areas of $\beta$-sheet structures in HOSEpiC were significantly lower than that in ES2 and higher than that in SKOV3 [(25.45 \pm $0.07) \%$ vs. $(26.55 \pm 0.36) \%,(25.45 \pm 0.07) \%$ vs. $(23.71 \pm$ $0.35) \%]$, while the band areas of $\alpha$-helical structures in HOSEpiC were significantly higher than that in ES2 and lower than that in SKOV3 $[(16.39 \pm 0.04) \%$ vs. $(15.51 \pm$ $0.04) \%,(16.39 \pm 0.04) \%$ vs. $(18.09 \pm 0.23) \%]$. HOSEpiC also had a higher band area of $\beta$-turn structures than ES2 [(50.92 \pm 0.17$) \%$ vs. $(50.09 \pm 0.37) \%]$. There also seemed significant differences between normal and some cancer cells and differences among the different types of ovarian cancer cells (Fig. 4, Table 1). These findings indicated that the secondary structure of protein had been altered in some but not all types of cancer cells, probably attributed to cell specificity.

\section{Subtraction spectrum of the ovarian cancer cells vs. normal cells}

In order to further indentify the differences between normal cells and ovarian cancer cells, subtraction spectrum was performed for each of the cancer cell line vs. HOSEpiC, respectively. In subtraction spectra, the differences between the two samples in details were observed visibly. For example, if we have A and B spectra, adjusting subtraction factor using subtraction spectrum is performed, and the positive and negative bands were clearly observed. $A-B$, the same components of $A$ and $B$ were subtracted out; positive bands represent the part $A>B$, while negative bands represent the part $\mathrm{B}>\mathrm{A}[38,39]$. As showing in Fig. 5, positive bands, indicating higher amounts, were seen in the region $3600-3000 \mathrm{~cm}^{-1}\left(v_{\mathrm{N}-\mathrm{H}}\right.$ of protein) as well as at the bands around $1655 \mathrm{~cm}^{-1}, 1548 \mathrm{~cm}^{-1}$ and $1406 \mathrm{~cm}^{-1}$ in all of the ovarian cancer cells. Negative bands, indicating lower amounts, were seen at the bands around $2922 \mathrm{~cm}^{-1}, 2852 \mathrm{~cm}^{-1}$ and $1741 \mathrm{~cm}^{-1}$ in ES2, A2780, OVCAR3 and IGROV1; negative bands for the subtraction spectrum of SKOV3 vs. HOSEpiC were seen at $2958 \mathrm{~cm}^{-1}, 2852 \mathrm{~cm}^{-1}$ and $1741 \mathrm{~cm}^{-1}$. These were consistent with our above results that lower amounts in lipids (3000-2800 $\mathrm{cm}^{-1}$ ) were found in ovarian cancer cells as compared to HOSEpiC cells, and that the signal at $1741 \mathrm{~cm}^{-1}$ was enhanced in HOSEpiC cells than in ovarian cancer cells. Increased amount at the band $1406 \mathrm{~cm}^{-1}$ also indicated decreased ratio of 1454/1400 in ovarian cancer cells. These findings also suggested that ovarian cancer cells might have higher amount of protein (3600-3000 $\mathrm{cm}^{-1}, 1655 \mathrm{~cm}^{-1}$ and $1548 \mathrm{~cm}^{-1}$ ) than normal cells. As proteins play crucial role in the physiological processes, the alteration of conformation and content of proteins in cancer cells may indicate a diversified and impending energy demands for the metabolism of malignant cells.

FTIR spectra analysis of normal and ovarian cancer tissues To further confirm the data derived from ovarian cancer cell lines vs. HOSEpiC cell line, the FTIR spectra of normal and ovarian cancer tissues from 12 patients were analyzed. There were significant differences between normal and cancerous tissues identified in the regions $3000-2800 \mathrm{~cm}^{-1}, 1500-1300 \mathrm{~cm}^{-1}$ and $1300-900 \mathrm{~cm}^{-1}$ (Fig. 6). 


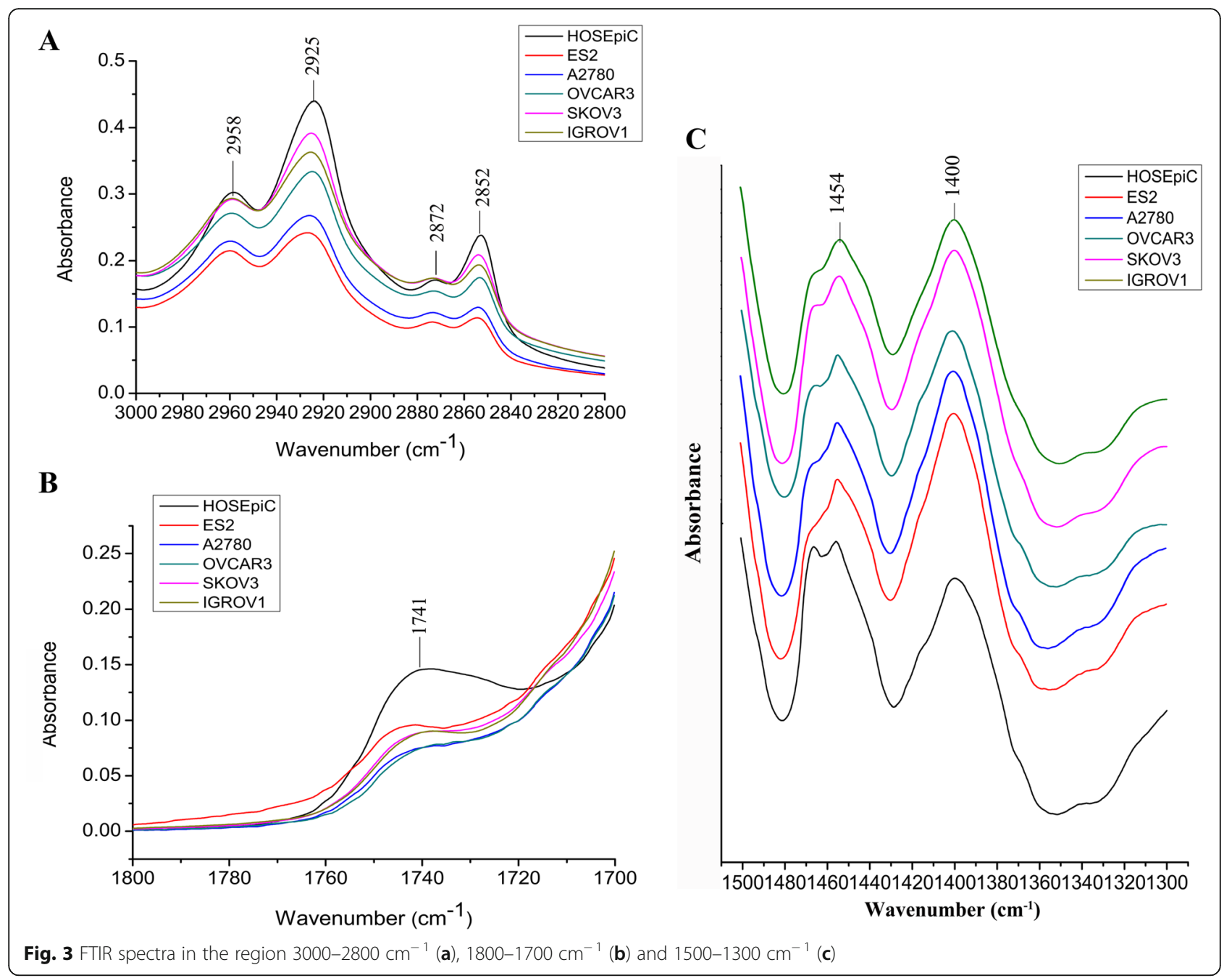

Table 1 Percentage of component band areas after Curve Fitting procedure in the region $1700-1600 \mathrm{~cm}^{-1}$

\begin{tabular}{|c|c|c|c|c|c|c|c|}
\hline \multirow[t]{2}{*}{ Position } & \multicolumn{6}{|l|}{ Area (\%) } & \multirow[t]{2}{*}{ Assignment } \\
\hline & HOSEpiC & ES2 & $\mathrm{A} 2780$ & OVCAR3 & SKOV3 & IGROV1 & \\
\hline 1629 & $9.46 \pm 0.12$ & $9.45 \pm 0.02$ & $9.66 \pm 0.15$ & $9.40 \pm 0.04$ & $8.91 \pm 0.17$ & $9.43 \pm 0.12$ & $\beta$-sheet \\
\hline 1639 & $15.99 \pm 0.18$ & $17.10 \pm 0.35$ & $15.67 \pm 0.28$ & $15.18 \pm 0.47$ & $14.80 \pm 0.17$ & $16.16 \pm 0.17$ & $\beta$-sheet \\
\hline$\beta$-sheet SUM & $25.45 \pm 0.07$ & $26.55 \pm 0.36$ & $25.33 \pm 0.43$ & $24.58 \pm 0.50$ & $23.71 \pm 0.35$ & $25.59 \pm 0.06$ & $\beta$-sheet SUM \\
\hline 1649 & $16.39 \pm 0.04$ & $15.51 \pm 0.04$ & $16.46 \pm 0.25$ & $16.89 \pm 0.29$ & $18.09 \pm 0.23$ & $16.58 \pm 0.17$ & a-helical \\
\hline 1657 & $22.86 \pm 0.30$ & $21.09 \pm 0.35$ & $22.34 \pm 0.06$ & $22.44 \pm 0.24$ & $23.46 \pm 0.11$ & $23.64 \pm 0.11$ & $\beta$-turn \\
\hline 1667 & $9.38 \pm 0.16$ & $9.82 \pm 0.29$ & $9.66 \pm 0.08$ & $9.53 \pm 0.09$ & $9.60 \pm 0.15$ & $9.35 \pm 0.15$ & $\beta$-turn \\
\hline 1674 & $5.13 \pm 0.10$ & $5.66 \pm 0.06$ & $5.31 \pm 0.15$ & $5.05 \pm 0.05$ & $4.70 \pm 0.05$ & $4.77 \pm 0.04$ & $\beta$-turn \\
\hline 1681 & $13.55 \pm 0.13$ & $13.52 \pm 0.25$ & $13.32 \pm 0.58$ & $14.32 \pm 0.44$ & $13.15 \pm 0.06$ & $13.26 \pm 0.07$ & $\beta$-turn \\
\hline$\beta$-turn SUM & $50.92 \pm 0.17$ & $50.09 \pm 0.37$ & $50.63 \pm 0.41$ & $51.34 \pm 0.24$ & $50.91 \pm 0.07$ & $51.02 \pm 0.06$ & $\beta$-turn SUM \\
\hline 1693 & $7.24 \pm 0.20$ & $7.85 \pm 0.03$ & $7.58 \pm 0.23$ & $7.19 \pm 0.03$ & $7.29 \pm 0.05$ & $6.81 \pm 0.18$ & \\
\hline
\end{tabular}

Bold texts indicate the area percentages of $\beta$-sheet, $a$-helical and $\beta$-turn structures, respectively 

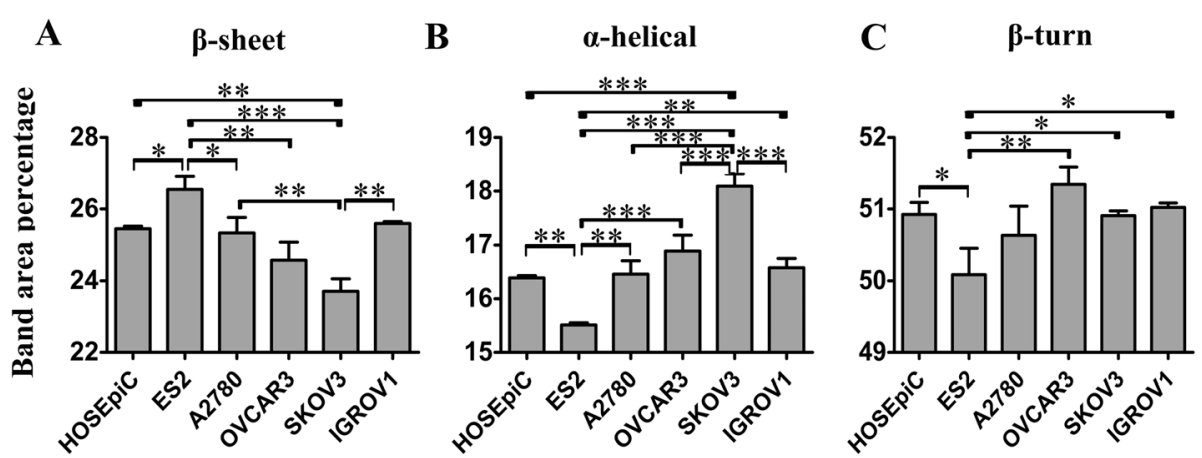

Fig. 4 Percentage of secondary structures of protein Amide I in normal and ovarian cancer cells. (a) $\beta$-sheet, (b) a-helix, (c) $\beta$-turn structures. Error bars represent the SEM, $n=3$ (*: $P<0.05$. **: $P<0.01$. $\left.{ }^{* *}: P<0.001\right)$

Malignant tissues showed lower absorption signals in $3000-2800 \mathrm{~cm}^{-1}$. The relative intensities of $2925 \mathrm{~cm}^{-1}$ and $2854 \mathrm{~cm}^{-1}$ were lower in malignant tissues and higher in normal tissues (Fig. 6); the differences were significant $(P=0.010,0.023$, respectively). Moreover, ten and eight ovarian cancer patients respectively showed lower absorption levels of $2925 \mathrm{~cm}^{-1}$ and $2854 \mathrm{~cm}^{-1}$ in malignant tissues (Fig. 7a, b), suggesting a decreased amount of lipids in malignant tissues. These results were consistent with the above cell line data.

For the absorption signal at around $1741 \mathrm{~cm}^{-1}$, there was no significant difference $(P=0.239)$ between normal and malignant tissues, although there were still 9 in 12 patients showed lower signals at this peak in malignant tissues (Fig. 7c). Cell line data showed no significant differences between HOSEpiC and other five cancer cell lines at the band intensities of $1242 \mathrm{~cm}^{-1}$ and $1086 \mathrm{~cm}^{-}$ ${ }^{1}$, however, malignant tissues showed significantly lower intensities at $1242 \mathrm{~cm}^{-1}$ and $1086 \mathrm{~cm}^{-1}$ than normal tissues $(P=0.003,0.002)$, and almost all the cancerous samples had the same decrease (11/12, 12/12; Fig. 7d, e). These findings indicated lower amount of nucleic acids in malignant tissues, and $1242 \mathrm{~cm}^{-1}$ and $1086 \mathrm{~cm}^{-1}$ might have been new spectra signatures to distinguish normal and ovarian cancer tissues.

The relative band intensity ratios of $1454 / 1400$ were significantly lower in malignant tissues than normal tissues in all of the ovarian cancer patients $(P=0.002$;

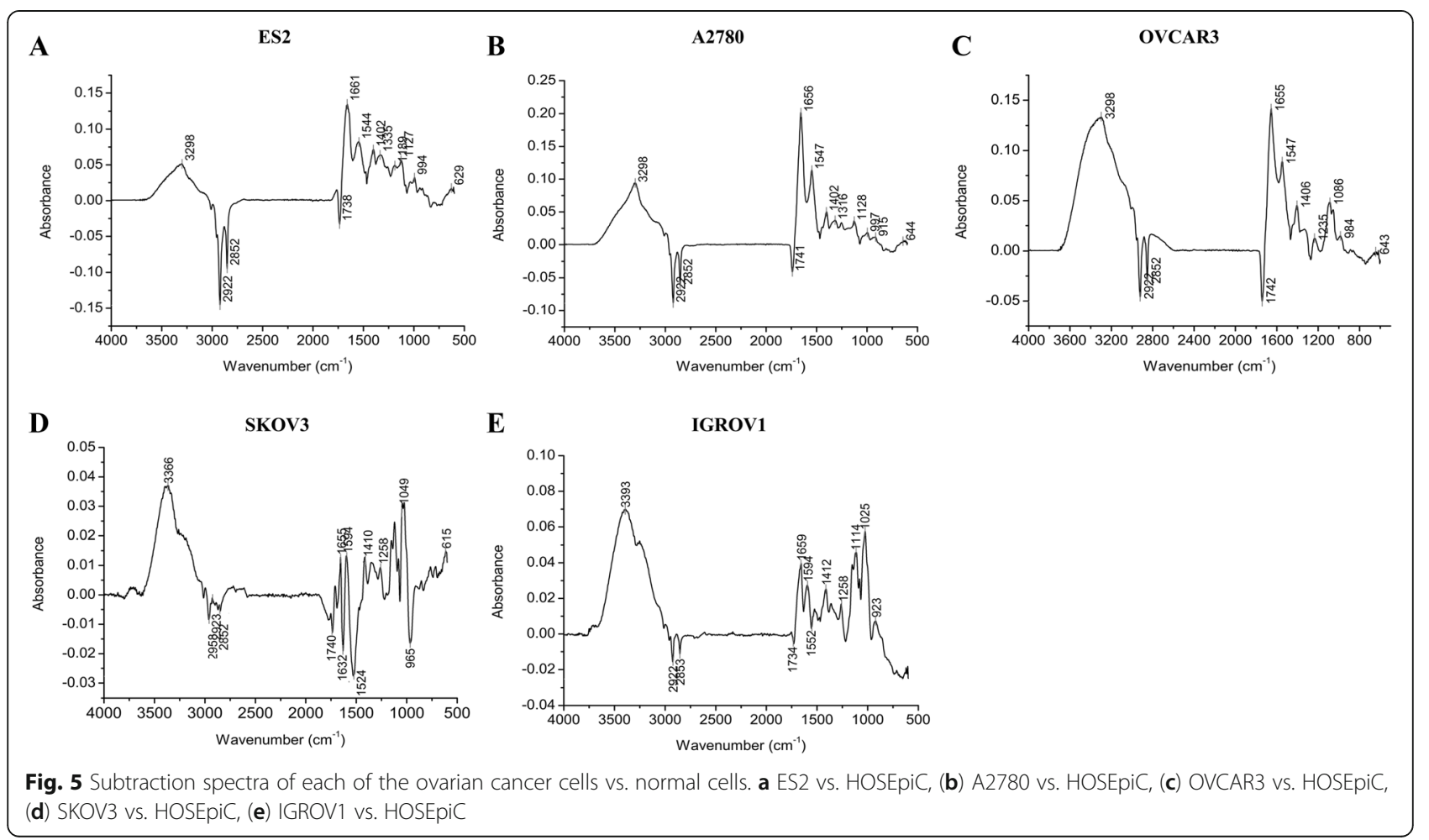




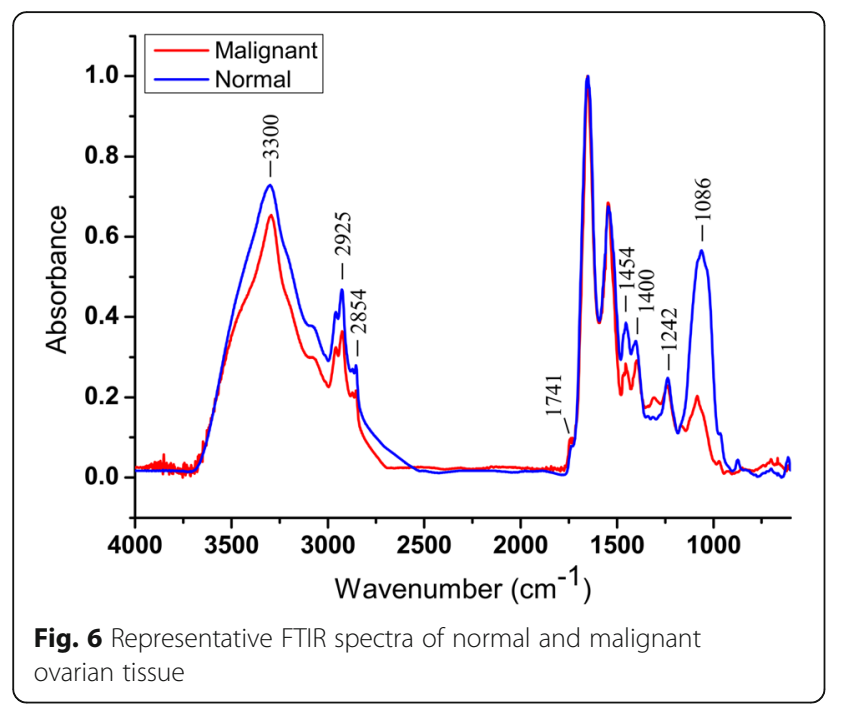

12/12). Cell line data above concluded that the ratios were $I_{1454} / I_{1400}>1$ for normal cells and $I_{1454} / I_{1400}<1$ for cancer cells, however, there were 9 patients with $I_{1454} /$ $I_{1400} \geq 1$ in normal tissues and 11 patients with $I_{1454} /$ $I_{1400}<1$ in malignant tissues (Fig. 7f). Not all of the tissues coincided with the cell line results. Integrating the cell line data with the tissue data, it was undoubtedly to conclude that normal tissues showed higher 1454/ 1400 ratios than its corresponding malignant tissues.

Cell line data analyzed that ovarian cancer cell lines might have higher amount of protein than normal cells, however, the results of the tissue samples were the opposite. Most patients exhibited lower signal levels of $3300 \mathrm{~cm}^{-1}$ and $1544 \mathrm{~cm}^{-1}$ in malignant tissues (Fig. $7 \mathrm{~g}, \mathrm{~h}$ ), indicating that the spectra feature of protein was debatable and needed further investigation.

\section{Discussion}

This study investigated the spectroscopic method to the identification of ovarian cancer. FTIR spectra were first analyzed on normal human ovarian surface epithelial cell line (HOSEpiC) and ovarian cancer cell lines (ES2,

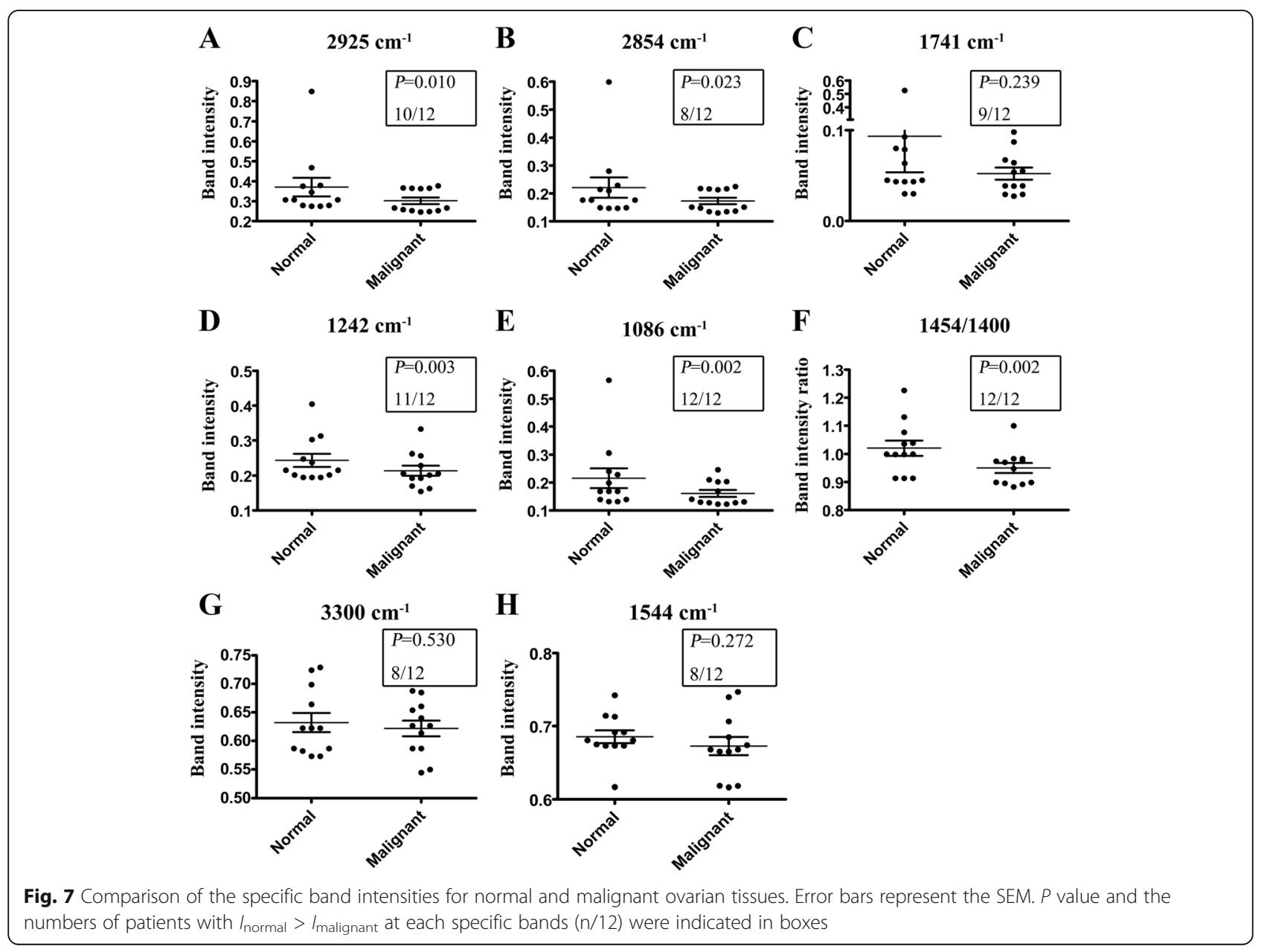


A2780, OVCAR3, SKOV3 and IGROV1) at the molecular level in order to a better understanding of their ingredients and contents. The analysis was performed on the spectral ranges of $\mathrm{CH}_{2}, \mathrm{CH}_{3}$ and $\mathrm{C}=\mathrm{O}$ stretching modes of lipids, Amide I band, and $v_{\mathrm{as}} \mathrm{PO}_{2}{ }^{-}$and $v_{\mathrm{s}} \mathrm{PO}_{2}{ }^{-}$ of nucleic acids. The differences between normal cells and ovarian cancer cells were highlighted including (1) a decrease in lipid synthesis $\left(3000-2800 \mathrm{~cm}^{-1}\right)$ in ovarian cancer cells; (2) lower amount of phospholipids in cell membrane $\left(1741 \mathrm{~cm}^{-1}\right)$ in cancer cells; (3) the different proportion of the band intensity of $\sim 1454$ and $1400 \mathrm{~cm}^{-1}$ in normal cells and in cancer cells, usually $\mathrm{I}_{1454} / \mathrm{I}_{1400} \geq 1$ for normal cells and $\mathrm{I}_{1454} / \mathrm{I}_{1400}<1$ for cancer cells; (4) an increase in protein amount (Amide I, Amide II and $v_{\mathrm{N}-\mathrm{H}}$ of proteins) in cancer cells.

These results were then verified by tissue samples from 12 ovarian cancer patients. FTIR spectra were compared and analyzed between normal tissues and the corresponding cancer tissues. However, there was no significant difference between normal and malignant tissues at the band intensity of $1741 \mathrm{~cm}^{-1}$. The spectra features of protein $\left(3300 \mathrm{~cm}^{-1}\right.$ and $\left.1544 \mathrm{~cm}^{-1}\right)$ were also not consistent with the cell line results. The intensity ratios of 1454/1400 were still lower in malignant tissues and higher normal tissues; however, $I_{1454} / I_{1400}>1$ or $<1$ was not the accurate criterion to distinguish normal and cancerous tissues. In addition, lower levels of nucleic acids $\left(1242 \mathrm{~cm}^{-1}\right.$ and $1086 \mathrm{~cm}^{-1}$ ) were observed in malignant tissues; however, this result was not summarized by cell line data. To integrate cell line data with tissue sample data, we can conclude that the differences between normal and ovarian cancer tissues were included (1) a decrease in lipid synthesis in malignant tissues; (2) lower amount of nucleic acids in malignant tissues; (3) normal tissues showed higher $1454 / 1400$ ratios than malignant tissues. These results have shown the remarkable spectra differences between normal and ovarian cancer cells/tissues with respect to their intensities of the prominent bands of cellular molecules, reflecting changes in the contents of proteins, nucleic acids and lipids. Cell line data also showed heterogeneity existing between different types of ovarian cancer cells. They differed in the synthesis of lipids and nucleic acids. The secondary structure of protein had also been altered between different types of cancer cells, indicating the appearance of new proteins and the alterations in their conformation and composition [23]. As for the data from tissue samples from 12 ovarian cancer patients, there were 10 serous and 2 clear cell cancer. However, no spectra differences were observed between the two types. This may because the sample size was quite small, and it might not be able to summarize the differences.

\section{Conclusions}

Although the results have considerable significance, more reliable evidences from tissue samples with heterogeneous subtypes are necessary to establish the specific and accurate spectral features that could classify malignant ovarian tissues from the normal tissues, as well as identify the precise type and status of malignant tissues. Spectral absorption modes of several heterogeneous ovarian cancer cell lines and some tissue samples primarily provide a research model and proof of principal that there are differences between EOC and healthy donor epithelium, and that this forms the evidences that further investigation is justified. Based on this, in the further study the FTIR spectrum, or prospectively in combination with other assistant methods, would be a useful diagnostic approach for ovarian cancer.

\section{Abbreviations}

ATR-FTIR: Attenuated total reflection Fourier-transform infrared; CA125: Serum Cancer Antigen 125; CT: Computed Tomography; DII: Second Derivative; EOC: Epithelial ovarian cancer; FTIR: Fourier Transform Infrared; HGSOC: High-grade serous ovarian cancer; HOSEpiC: Human ovarian surface epithelial cell line; MRI: Magnetic Resonance Imaging

\section{Funding}

This study was supported by the National Natural Science Foundation of China (NO. 81502254) and the Chinese Academy of Medical Sciences Initiative for Innovative Medicine (CAMS-2017-I2M-1-002).

\section{Availability of data and materials}

The dataset supporting the conclusions of this article is included within the article.

\section{Authors' contributions}

Conception and design: LL, JW, YX, KS; Funding acquisition: LL, KS; Data Acquisition: LL, JW, XB, HS, SW; Data analysis: LL, JW, SW, LY, YB; Project administration: $L L, J W, K S$; Investigation: $L L, J W, L Y$; Writing original draft: $L L$, JW; Revising and editing: MY, YZ, JW, SL. All authors read and approved the final manuscript.

Ethics approval and consent to participate

Peking Union Medical College Hospital Human Research Ethics Committee Approval was obtained for the use of all samples.

Consent for publication

Not applicable.

\section{Competing interests}

The authors declare that they have no competing interests.

\section{Publisher's Note}

Springer Nature remains neutral with regard to jurisdictional claims in published maps and institutional affiliations.

\section{Author details}

${ }^{1}$ Department of Obstetrics and Gynecology, Peking Union Medical College Hospital, Chinese Academy of Medical Sciences \& Peking Union Medical College, No. 1 Shuai Fu Yuan, Eastern District, Beijing 100730, China. ${ }^{2}$ Beijing National Laboratory for Molecular Sciences, State Key Laboratory for Rare Earth Materials Chemistry and Applications, College of Chemistry and Molecular Engineering, Peking University, No. 202 Chengfu Road, Haidian District, Beijing 100871, China. ${ }^{3}$ State Key Laboratory of Nuclear Physics and Technology, Institute of Heavy Ion Physics, School of Physics, Peking University, No. 202 Chengfu Road, Haidian District, Beijing 100871, China. 
Received: 6 May 2018 Accepted: 18 July 2018

Published online: 02 August 2018

\section{References}

1. Ferlay J, Soerjomataram I, Dikshit R, Eser S, Mathers C, Rebelo M, Parkin DM, Forman D, Bray F. Cancer incidence and mortality worldwide: sources, methods and major patterns in GLOBOCAN 2012. Int J Cancer. 2015;136(5): E359-86.

2. Pierredon S, Ribaux P, Tille JC, Petignat P, Cohen M. Comparative secretome of ovarian serous carcinoma: gelsolin in the spotlight. Oncol Lett. 2017;13(6): 4965-73.

3. Chuaqui RF, Cole KA, Emmert-Buck MR, Merino MJ. Histopathology and molecular biology of ovarian epithelial tumors. Ann Diagn Pathol. 1998;2(3): 195-207.

4. Seidman JD, Horkayne-Szakaly I, Haiba M, Boice CR, Kurman RJ, Ronnett BM. The histologic type and stage distribution of ovarian carcinomas of surface epithelial origin. Int J Gynecol Pathol. 2004;23(1):41-4.

5. Gershenson DM, Sun CC, Lu KH, Coleman RL, Sood AK, Malpica A, Deavers MT, Silva EG, Bodurka DC. Clinical behavior of stage II-IV low-grade serous carcinoma of the ovary. Obstet Gynecol. 2006;108(2):361-8.

6. Fritsche HA, Bast RC. CA 125 in ovarian cancer: advances and controversy. Clin Chem. 1998:44(7):1379-80.

7. Togashi K. Ovarian cancer: the clinical role of US, CT, and MRI. Eur Radiol. 2003;13(Suppl 4):L87-104.

8. O'Rourke J, Mahon SM. A comprehensive look at the early detection of ovarian cancer. Clin J Oncol Nurs. 2003:7(1):41-7.

9. Martin FL. Shining a new light into molecular workings. Nat Methods. 2011; 8(5):385-7.

10. Baker MJ, Trevisan J, Bassan P, Bhargava R, Butler HJ, Dorling KM, Fielden PR, Fogarty SW, Fullwood NJ, Heys KA, Hughes C, Lasch P, Martin-Hirsch PL, Obinaju B, Sockalingum GD, Sule-Suso J, et al. Using Fourier transform IR spectroscopy to analyze biological materials. Nat Protoc. 2014;9(8):1771-91.

11. Jackson M, Sowa MG, Mantsch HH. Infrared spectroscopy: a new frontier in medicine. Biophys Chem. 1997;68(1-3):109-25.

12. Taillandier E, Liquier J. Infrared spectroscopy of DNA. Methods Enzymol. 1992;211:307-35.

13. Andrus PG, Strickland RD. Cancer grading by Fourier transform infrared spectroscopy. Biospectroscopy. 1998;4(1):37-46.

14. Wood BR, Quinn MA, Tait B, Ashdown M, Hislop T, Romeo M, McNaughton D. FTIR microspectroscopic study of cell types and potential confounding variables in screening for cervical malignancies. Biospectroscopy. 1998;4(2):75-91.

15. Taylor SE, Cheung KT, Patel II, Trevisan J, Stringfellow HF, Ashton KM, Wood NJ, Keating PJ, Martin-Hirsch PL, Martin FL. Infrared spectroscopy with multivariate analysis to interrogate endometrial tissue: a novel and objective diagnostic approach. Br J Cancer. 2011;104(5):790-7.

16. Sindhuphak R, Issaravanich $S$, Udomprasertgul V, Srisookho P, Warakamin S, Sindhuphak S, Boonbundarlchai R, Dusitsin N. A new approach for the detection of cervical cancer in Thai women. Gynecol Oncol. 2003;90(1):10-4.

17. Kelly JG, Ahmadzai AA, Hermansen P, Pitt MA, Saidan Z, Martin-Hirsch PL, Martin FL. A biospectroscopic interrogation of fine needle aspirates points towards segregation between graded categories: an initial study towards diagnostic screening. Anal Bioanal Chem. 2011;401(3):957-67.

18. Das RM, Ahmed MK, Mantsch HH, Scott JE. FT-IR spectroscopy of methylmercury-exposed mouse lung. Mol Cell Biochem. 1995;145(1):75-9.

19. Gajjar K, Heppenstall LD, Pang W, Ashton KM, Trevisan J, Patel II, Llabjani V, Stringfellow HF, Martin-Hirsch PL, Dawson T, Martin FL. Diagnostic segregation of human brain tumours using Fourier-transform infrared and/or Raman spectroscopy coupled with discriminant analysis. Anal Methods. 2012;5:89-102.

20. Gajjar K, Trevisan J, Owens G, Keating PJ, Wood NJ, Stringfellow HF, MartinHirsch PL, Martin FL. Fourier-transform infrared spectroscopy coupled with a classification machine for the analysis of blood plasma or serum: a novel diagnostic approach for ovarian cancer. Analyst. 2013;138(14):3917-26.

21. Owens GL, Gajjar K, Trevisan J, Fogarty SW, Taylor SE, Da Gama-Rose B, Martin-Hirsch PL, Martin FL. Vibrational biospectroscopy coupled with multivariate analysis extracts potentially diagnostic features in blood plasma/serum of ovarian cancer patients. J Biophotonics. 2014;7(3-4):200-9.

22. Lima KM, Gajjar KB, Martin-Hirsch PL, Martin FL. Segregation of ovarian cancer stage exploiting spectral biomarkers derived from blood plasma or serum analysis: ATR-FTIR spectroscopy coupled with variable selection methods. Biotechnol Prog. 2015;31(3):832-9.
23. Mehrotra R, Tyagi G, Jangir DK, Dawar R, Gupta N. Analysis of ovarian tumor pathology by Fourier transform infrared spectroscopy. J Ovarian Res. 2010;3:27.

24. Theophilou G, Lima KM, Martin-Hirsch PL, Stringfellow HF, Martin FL. ATRFTIR spectroscopy coupled with chemometric analysis discriminates normal, borderline and malignant ovarian tissue: classifying subtypes of human cancer. Analyst. 2016;141(2):585-94.

25. Hamilton TC, Young RC, McKoy WM, Grotzinger KR, Green JA, Chu EW, Whang-Peng J, Rogan AM, Green WR, Ozols RF. Characterization of a human ovarian carcinoma cell line (NIH:OVCAR-3) with androgen and estrogen receptors. Cancer Res. 1983;43(11):5379-89.

26. Domcke S, Sinha R, Levine DA, Sander C, Schultz N. Evaluating cell lines as tumour models by comparison of genomic profiles. Nat Commun. 2013;4:2126.

27. Lau DH, Lewis AD, Ehsan MN, Sikic Bl. Multifactorial mechanisms associated with broad cross-resistance of ovarian carcinoma cells selected by cyanomorpholino doxorubicin. Cancer Res. 1991;51(19):5181-7.

28. Benard J, Da Silva J, De Blois MC, Boyer P, Duvillard P, Chiric E, Riou G. Characterization of a human ovarian adenocarcinoma line, IGROV1, in tissue culture and in nude mice. Cancer Res. 1985;45(10):4970-9.

29. Dong L, Sun X, Chao Z, Zhang S, Zheng J, Gurung R, Du J, Shi J, Xu Y, Zhang $Y$, Wu J. Evaluation of FTIR spectroscopy as diagnostic tool for colorectal cancer using spectral analysis. Spectrochim Acta A Mol Biomol Spectrosc. 2014;122:288-94.

30. Gioacchini G, Giorgini E, Vaccari L, Ferraris P, Sabbatini S, Bianchi V, Borini A, Carnevali $O$. A new approach to evaluate aging effects on human oocytes: Fourier transform infrared imaging spectroscopy study. Fertil Steril. 2014; 101(1):120-7.

31. Wood BR, Chiriboga L, Yee H, Quinn MA, McNaughton D, Diem M. Fourier transform infrared (FTIR) spectral mapping of the cervical transformation zone, and dysplastic squamous epithelium. Gynecol Oncol. 2004;93(1):59-68.

32. Derenne A, Van Hemelryck V, Lamoral-Theys D, Kiss R, Goormaghtigh E. FTIR spectroscopy: a new valuable tool to classify the effects of polyphenolic compounds on cancer cells. Biochim Biophys Acta. 2013;1832(1):46-56.

33. Gaigneaux A, Ruysschaert JM, Goormaghtigh E. Infrared spectroscopy as a tool for discrimination between sensitive and multiresistant K562 cells. Eur J Biochem. 2002;269(7):1968-73.

34. Wu BB, Gong $Y P$, Wu XH, Chen $Y Y$, Chen FF, Jin LT, Cheng BR, Hu F, Xiong B. Fourier transform infrared spectroscopy for the distinction of MCF-7 cells treated with different concentrations of 5-fluorouracil. J Transl Med. 2015;13:108.

35. Gao $Y$, Huo X, Dong L, Sun X, Sai H, Wei G, Xu Y, Zhang Y, Wu J. Fourier transform infrared microspectroscopy monitoring of 5-fluorouracil-induced apoptosis in SW620 colon cancer cells. Mol Med Rep. 2015;11(4):2585-91.

36. Glassford SE, Byrne B, Kazarian SG. Recent applications of ATR FTIR spectroscopy and imaging to proteins. Biochim Biophys Acta. 2013; 1834(12):2849-58.

37. Susi H, Byler DM. Resolution-enhanced Fourier transform infrared spectroscopy of enzymes. Methods Enzymol. 1986;130:290-311.

38. Gezici O, Demir I, Demircan A, Unlu N, Karaarslan M. Subtractive-FTIR spectroscopy to characterize organic matter in lignite samples from different depths. Spectrochim Acta A Mol Biomol Spectrosc. 2012;96:63-9.

39. Derenne A, Verdonck M, Goormaghtigh E. The effect of anticancer drugs on seven cell lines monitored by FTIR spectroscopy. Analyst. 2012;137(14):3255-64

Ready to submit your research? Choose BMC and benefit from:

- fast, convenient online submission

- thorough peer review by experienced researchers in your field

- rapid publication on acceptance

- support for research data, including large and complex data types

- gold Open Access which fosters wider collaboration and increased citations

- maximum visibility for your research: over $100 \mathrm{M}$ website views per year

At BMC, research is always in progress.

Learn more biomedcentral.com/submissions 